\title{
RASAMOELINA Henri, Madagascar. État, communautés villageoises et banditisme rural
}

Paris, L'Harmattan, 2007, 250 p., ISBN : 978-2-296-03873-3

\section{Gilles Ferréol}

\section{OpenEdition}

\section{Journals}

Édition électronique

URL : https://journals.openedition.org/remi/4712

DOI : $10.4000 /$ remi. 4712

ISSN : $1777-5418$

Éditeur

Université de Poitiers

Édition imprimée

Date de publication : 1 novembre 2008

Pagination : 219

ISBN : 978-2-911627-49-0

ISSN : 0765-0752

\section{Référence électronique}

Gilles Ferréol, «RASAMOELINA Henri, Madagascar. État, communautés villageoises et banditisme rural », Revue européenne des migrations internationales [En ligne], vol. 24 - n² | 2008, mis en ligne le 16 décembre 2008, consulté le 15 avril 2022. URL : http://journals.openedition.org/remi/4712 ; DOI : https://doi.org/10.4000/remi.4712 


\section{NOTES DE LECTURE}

\section{RASAMOELINA Henri}

Madagascar. État, communautés villageoises et banditisme rural, Paris, L'Harmattan, 2007, $250 \mathrm{p}$.

ISBN : 978-2-296-03873-3

Dans une préface très éclairante, Jean Pavageau souligne d'emblée que "le vol de zébu, au même titre que le retournement des morts, est depuis toujours présenté comme une spécificité de la culture malgache, une pratique curieuse et exotique qui perdure encore de nos jours » (p. 7). Sa signification a cependant beaucoup évolué au fil du temps : de rituel de passage et d'affirmation identitaire à travers des affrontements entre jeunes d'un même clan, puis entre groupes rivaux, on est passé peu à peu à des préoccupations ou à de enjeux mercantiles et, plus récemment, à une forme de contestation du système politique impliquant à plusieurs niveaux l'appareil d'État.

L'enquête minutieuse menée par Henri Rasaomelina, professeur de sociologie à l'université de Fianarantsoa, nous conduit en pays Betsileo, dans la Haute-Matsiatra, à la fois berceau de nombreux royaumes et région traditionnellement très touchée par ce fléau. Trois grandes parties composent cet ouvrage. La première, prenant appui sur des données tant territoriales que socio-historiques, nous livre des éléments de contextualisation et insiste non sans raison sur le poids du lignage (foko) et sur l'importance, dans la réalité quotidienne des familles et des communautés villageoises, du rôle et de la place du bæuf lequel, comme le faisait déjà observer en 1938 le Père Dubois dans l'un de ses écrits, est «celui qui est la richesse de tous et que l'on chante sur tous les tons; celui que l'on contemple sans se lasser, dont on connaît toutes les particularités et pour qui la langue se met en frais de dénomination selon l'âge, la taille, la robe, les mouvements ; celui aussi dont on tire partie de toutes les manières" (p. 38).

Après cette mise en perspective, l'auteur se focalise sur le XIX siècle, brigandage et insécurité étant alors le lot commun, à l'exception de deux décennies d'accalmie entre 1860 et
1880. Tous ces soubresauts sont mis en relation avec les changements intervenus dans les rapports de force au sein de la monarchie merina, l'influence des missionnaires et les tensions avec la France devant être également prises en compte.

Les trois derniers chapitres mettent respectivement l'accent sur les pressions exercées par l'administration coloniale après l'annexion de la Grande Ile, sur la relative stabilité des années 1960 et sur l'actuelle recrudescence du phénomène, avec - sur fond d'insatisfaction, de frustration ou de malaise social son cortège de coups et blessures, de trafic d'armes et de complicités...

Au terme de cette contribution bien documentée, il apparaît que la référence à un passé mythique, structuré autour de l'amour du prochain et de l'harmonie dans la parenté (fihavanana), doit être à bien des égard relativisée, la compréhension du "banditisme rural » et de sa figure emblématique (le dahalo) nécessitant une méthodologie adéquate.

Gilles FERRÉOL

Université de Franche-Comté (LASA, laboratoire de socio-anthropologie) 